\title{
DEFORMATION MONITORING IN ZAFARRAYA FAULT AND SIERRA TEJEDA ANTIFORM (BETIC CORDILLERA, SPAIN) USING SATELLITE RADAR INTERFEROMETRY
}

\author{
Antonio M. Ruiz-Armenteros ${ }^{(1,2,3)}$, J. Manuel Delgado ${ }^{(3,4)}$, Joaquim J. Sousa ${ }^{(5)}$, Ramon F. Hanssen ${ }^{(6)}$, \\ Miguel Caro $^{(7)}$, Antonio J. Gil ${ }^{(1,2,3)}$, Jesús Galindo-Zaldívar ${ }^{(8,9)}$, Carlos Sanz de Galdeano ${ }^{(9)}$ \\ ${ }^{(1)}$ Departamento de Ingeniería Cartográfica, Geodésica y Fotogrametría, Universidad de Jaén \\ Escuela Politécnica Superior de Jaén, Campus Las Lagunillas s/n, Edif. A3, 23071 Jaén, (Spain) \\ ${ }^{(2)}$ Centro de Estudios Avanzados en Ciencias de la Tierra CEACTierra, Universidad de Jaén \\ ${ }^{(3)}$ Grupo de investigación Microgeodesia Jaén, Universidad de Jaén \\ Email: amruiz@ujaen.es; ajgil@ujaen.es \\ (4) Progressive Systems Srl, Rome, (Italy),Email: JoseManuel.DelgadoBlasco@esa.int \\ ${ }^{(5)}$ Escola de Ciências e Tecnologia, Universidade de Trás-os-Montes e Alto Douro \\ Quinta de Prados Apartado 1013, 5001-801 Vila Real, (Portugal), Email: jjsousa@utad.pt \\ ${ }^{(6)}$ Department of Geoscience and Remote Sensing, Delft University of Technology, Stevinweg 1, 2628CN, Delft, \\ P.O. Box 5048, 2600GA Delft, (The Netherlands), Email: R.F.Hanssen@tudelft.nl \\ (7) Department of Radar Technology, TNO, The Hague, (The Netherlands), Email: miguel.carocuenca@tno.nl \\ ${ }^{(8)}$ Departamento de Geodinámica, Facultad de Ciencias, Universidad de Granada, \\ Campus de Fuentenueva, s/n, 18071 Granada, (Spain), Email: jgalindo@ugr.es \\ (9) Instituto Andaluz de Ciencias de la Tierra, Facultad de Ciencias, CSIC-Universidad de Granada, \\ Campus de Fuentenueva, s/n, 18071 Granada, (Spain),Email: csanz@ugr.es
}

\begin{abstract}
The Betic-Rif cordilleras are build-up in the western Mediterranean by the deformations related to the Eurasian-African plate boundary. The recent NW-SE convergence produces the simultaneous development of large folds and faults in the central part of the Internal Zones of the Betic Cordilleras, which continues active up to Present. The uplift of the mountain ranges is mainly related to the development of folds in this regional compressive setting. Sierra Tejeda constitutes a relief related to the development of a complex shaped recent antiform that is located near the coast line. At the northern limb of Sierra Tejeda is located the Zafarraya fault, a high-angle northwards dipping normal fault. Understanding the tectonic of the Zafarraya fault is crucial since one of the most destructive earthquakes ( $25^{\text {th }}$ December 1884$)$ on the Iberian Peninsula occurred along this fault (magnitude of 6.7). This paper investigates the applicability of satellite radar interferometry using ERS-1/2 SAR and Envisat ASAR datasets to help to constraint the geological hazard in this part of the Betic Cordillera.
\end{abstract}

\section{INTRODUCTION}

The Betic Chain, together with the Rif, constitutes the westernmost range of the Mediterranean Alpine Cordilleras. It is situated between the Eurasian-African plate boundary. Consequently, the deformation occurring in the Betic Chain corresponds to the relative movements of the plates.
The Betic Chain is fundamentally divided into External and Internal Zones. The External Zone constituted the Mesozoic and Tertiary cover of the S and SE part of the Iberian Paleozoic Shield. It is subdivided in Prebetic, located near the Paleozoic Shield, and Subbetic. Particularly, our area of interest includes the Subbetic. Geological formations present thick Jurassic series of limestones and dolomites, for instance in Sierra Gorda and Zafarraya sectors (Fig. 1).

The Internal Zone is situated south of the External one and it is formed by three superimposed complexes. From bottom to top, we find the Nevado-Filabride, the Alpujarride and the Malaguide. In the studied area only outcrops the Alpujarride and the Malaguide Complexes. The Alpujarride forms the Sierra Tejeda and surrounding near areas (Fig. 1). Their lithologic sequences are mainly formed by schists (Variscan to lower Triassic ages) in the bottom, and by limestone and dolomitic more than $700 \mathrm{~m}$ thick - Triassic marbles. These marbles constitutes the frame of the relief of Sierra Tejeda. The Malaguide Complex is situated to the SW of the studied area and there corresponds to Paleozoic schists, phyllites and even lutites.

During the Mesozoic and till the end of the Oligocene, the present Internal Zone was situated farther to the East, and just after its structuring in complexes. During the early Miocene, this zone underwent an important westwards drift (as consequence of the AfricanEurasian-Iberian convergence) and the opening of the Algero-Provençal basin in the western part of the Mediterranean. 
Finally, the present contact between the Internal and External Zones was formed corresponding to a very important dextral strike slip fault, although later deformed.

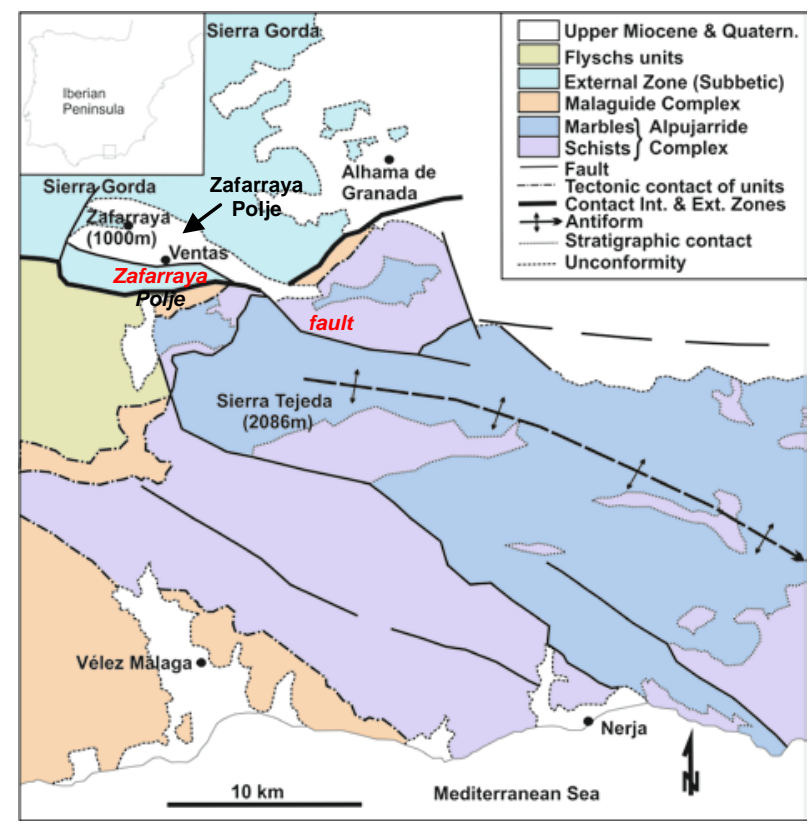

Figure 1. Geological settings of the study area.

From the later Miocene to the present, the convergence between Iberia and Africa (4 mm/year in a NW-SE direction; [1]) together with a certain continuity of the westwards displacement of the Internal Zone lead to dynamic situation in which a NNW-SSE to NW-SE compression is combined with an ENE-WSW extension. During this period new faults were formed and other older ones moved in different way with respect to their first displacements.

In this scenario, the main faults in the studied area (Fig. 1) are:

- The approximate E-W fault of the northern border of Sierra Tejeda. This fault formerly had a strike-slip character, but from the later Miocene has a predominant normal character, sinking the northern border. This fault continues to the west in the Zafarraya area. Probably this fault is the responsible of the strongest historic earthquake of the region, occurred on $25^{\text {th }}$ December 1884. Reference [2] described relative recent movements of this fault in the area of Zafarraya. In some points the throw of the fault easily surpassed the 1000 $\mathrm{m}$.

- The fault that marks the NW-SE limit of Sierra Tejeda. This fault is very segmented although, on the whole, took a former sinistral strike slip displacement, but at present also present normal character, sinking the SW border. The throw is less prominent than the one of the fault of the $\mathrm{N}$ of Sierra Tejeda.
Also, related to the NNW-SSE compression, Sierra Tejeda was gently folded in an approximate E-W direction (as occurred in other areas in the Betics, for instance the great antiform of Sierra Nevada). The antiform of Sierra Tejeda is superposed to a very complicated Alpine structure, where very tight folds are abundant.

Faults and folds contributed to the present elevation of Sierra Tejeda, giving a strong relief in comparison to the surrounding area.

According to this geological setting, the studied area presents several aspects of interest: the relation between the Internal and External Zone; the movements of the faults, particularly those of the main faults referred; and the continuity or not of the neotectonic to present folding of Sierra Tejeda. Our interest focuses on studying present displacements because they are narrowly linked to the tectonics mentioned above and their knowledge surely clarifies to understand how the region continues its evolution.

In this paper, we investigate the behaviour of this area of the Betic Cordillera in the period 1992-2008 by using satellite radar interferometry with ERS-1/2 and Envisat ASAR datasets.

\section{DATA AND METHOD}

\subsection{Satellite datasets}

The study area is covered by two different satellite tracks. One is the ERS-1/2 descending track 51, frame 2862 , from $05 / 05 / 1992$ to $28 / 12 / 2000$. The other is the Envisat ASAR ascending track 459, frame 731, from 21/03/2003 to 01/08/2008. Fig. 2 shows the distribution of these tracks over the study area. For this preliminary processing we selected 24 and 27 SLC scenes for ERS1/2 and Envisat respectively. Figs. 3 to 6 show the perpendicular and Doppler baselines distributions for the selected SLC scenes.

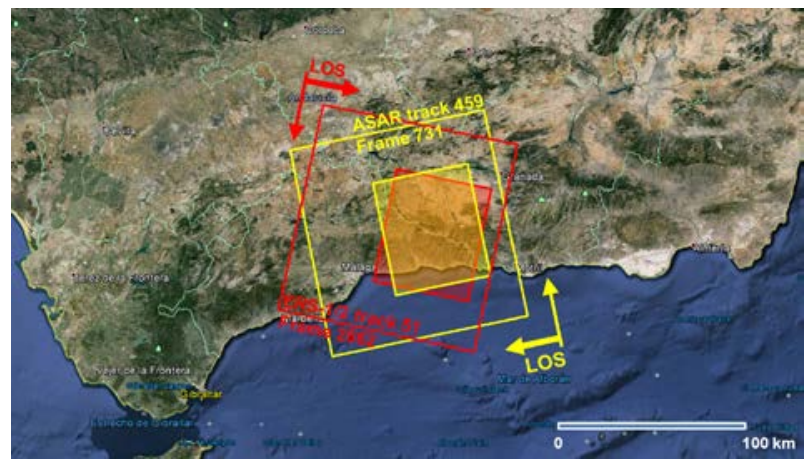

Figure 2. Satellite tracks and frames as well as processed crops (shahed areas) over the study area. 


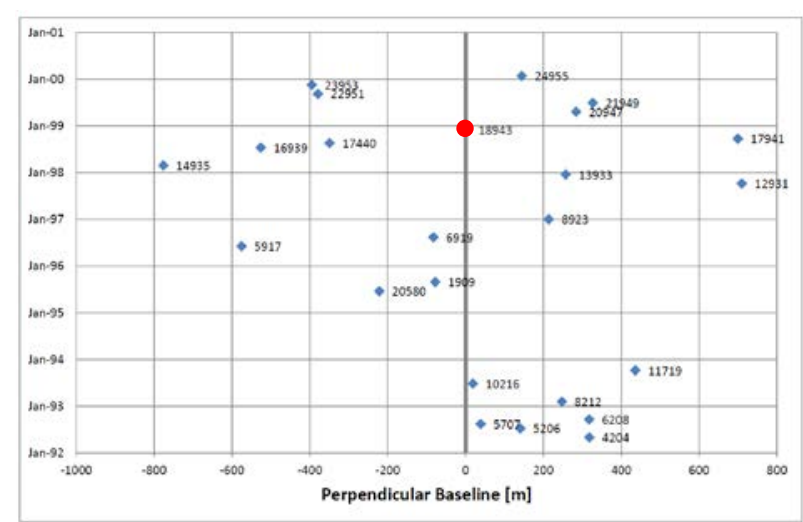

Figure 3. Perpendicular baseline distribution for the ERS-1/2 dataset used in this study. Master image is shown as a red dot.

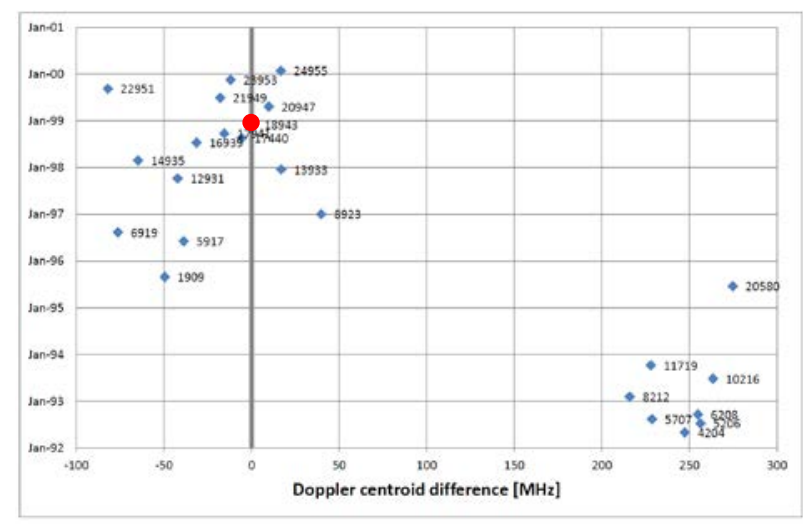

Figure 4. Doppler centroid difference distribution for the ERS-1/2 dataset used in this study. Master image is shown as a red dot.

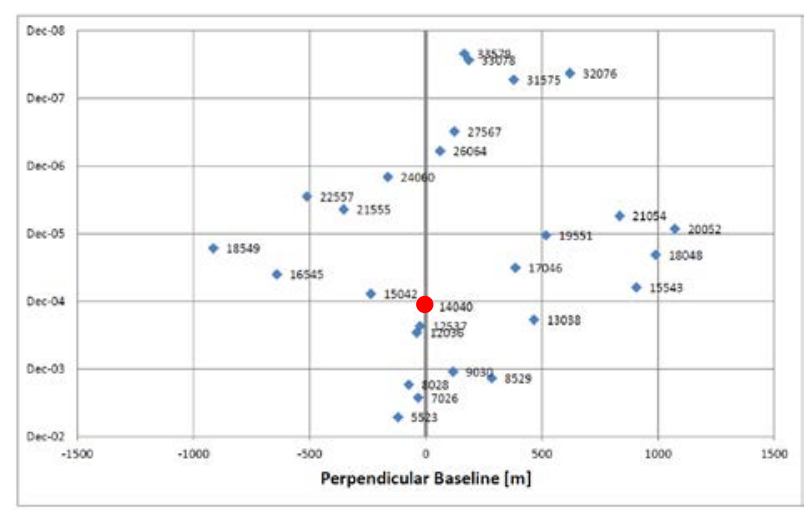

Figure 5. Perpendicular baseline distribution for the ASAR dataset used in this study. Master image is shown as a red dot.

\subsection{Processing methodology}

In this study, we apply radar interferometry InSAR to an area of 50 x $50 \mathrm{~km}^{2}$ centered in Zafarraya and Sierra Tejeda area (southern Spain). InSAR is a spaceborne technique that uses the phase differences between two

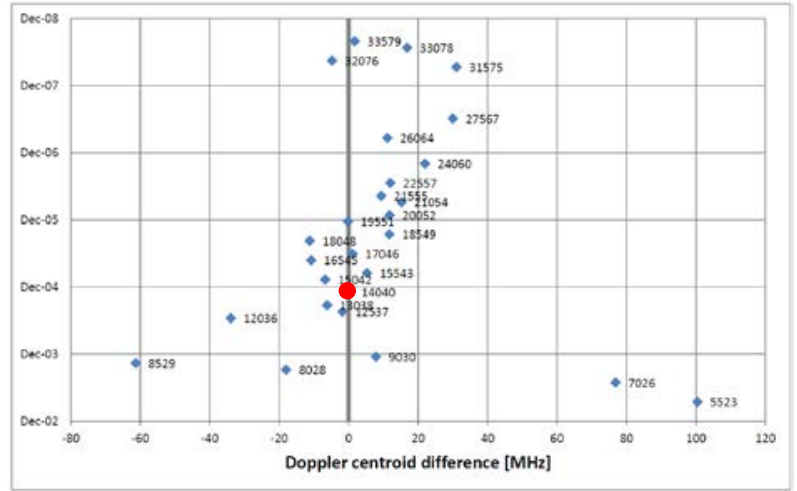

Figure 6. Doppler centroid difference distribution for the Envisat dataset used in this study. Master image is shown as a red dot.

radar images (i.e. interferograms) acquired over the same area at slightly different positions to estimate surface displacements, see e.g. [3]. The slow motion expected as well as the dimensions of the affected area make InSAR a very good candidate to estimate ground displacements in this area. Under the right conditions, InSAR is able to provide with millimeter accuracy displacements and with coverage of hundred $\mathrm{km}^{2}$.

For this study, we apply the time series analysis method of StaMPS/MTI (Stanford Method for Persistent Scatterers - Multi-Temporal InSAR) to extract the maximum number of reliable InSAR observations, by identifying both persistent scatterers (PS) pixels i.e. dominated by single scatterers and slowly-decorrelating filtered phase (SDFP) pixels, [4].

In this algorithm, PS and SDFP pixels are, at a first instance, independently processed. Thus, a series of single master interferograms are created for PS identification, see e.g. [5], [6] and [7]. PS are the pixels that remain coherent during the whole time spam.

Meanwhile the small baseline approach is applied to detect SDFP pixels, see, e.g. [8]. Small baseline refers to both short spatial (maximum of few hundreds of meters) and temporal differences (maximum of few months) between radar images. Therefore, SDFP pixels are detected because they remain coherent at short time scales. After spatial and temporal low-pass filter, the information concerning ground deformation can be extracted.

The StaMPS/MTI approach combines these two sets of observations before phase unwrapping, which is the process of estimating the total number of cycles in which the absolute phase is wrapped into. Phase unwrapping is a crucial step because an error in this process means an error of a quarter of the wavelength in the deformation time series (the wavelength of the radars used in this study is $56 \mathrm{~mm}$, corresponding to $\mathrm{C}$ band). Thus, StaMPS/MTI increases the density of observation 
to improve phase unwrapping and the posterior estimation derived from the unwrapped phases. Once observations are merged and time series unwrapped, atmospheric artifacts are estimated and removed. Atmospheric artifacts can be estimated by filtering the radar data as atmospheric signals are uncorreclated in time but correlated in space, or using ancillary data ([9]).

To remove the topographic phase in the interferometric processing we use a Digital Elevation Model with $25 \mathrm{~m}$ resolution provided by the Instituto Geográfico Nacional de España. In the same way, the reference phase was computed using highly precise orbit data for ERS-1/2 and Envisat satellites calculated by TU Delft ([10]) and ESA.

\section{RESULTS}

We applied the StaMPS/MTI method to the two datasets (ERS-1/2 descending and Envisat ascending) processing the crops shown as shaded areas in Fig. 2. For every stack we processed PSI, SB and the combined (PSI+SB) method. In the case of ERS-1/2, we selected the image of $4^{\text {th }}$ December 1998 as master image in the PSI processing. We formed 24 single master interferograms (Fig. 7) detecting 277743 stable-phase pixels (PS). For the SB processing, the network was composed of 56 interferograms (Fig. 8), selecting 266748 SDPF pixels. After their combination and recomputation of the unwrapped phase values, 483958 stable-phase pixels were selected for this area of about $50 \times 50 \mathrm{~km}^{2}$.

In the case of the Envisat dataset, we selected the image of $5^{\text {th }}$ November 2004 as master date. We constructed 27 and 83 interferograms for the PSI and SB processing respectively (Fig. 9 and 10). In the same way, 91826 and 309946 stable-phase pixels were identified in both processing methods. Finally, for the combined processing, 360512 PS pixels were selected.

Although is an area with both an important topography (heights from $0 \mathrm{~m}$ at sea level to close to $2000 \mathrm{~m}$ ) and vegetation, many phase-stable pixels were detected.

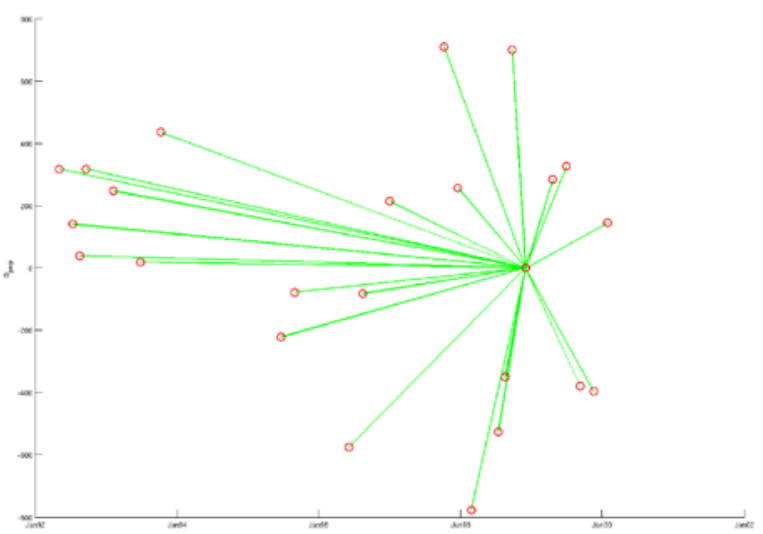

Figure 7. Temporal vs. spatial baseline distribution for the ERS-1/2 data in the PSI processing.

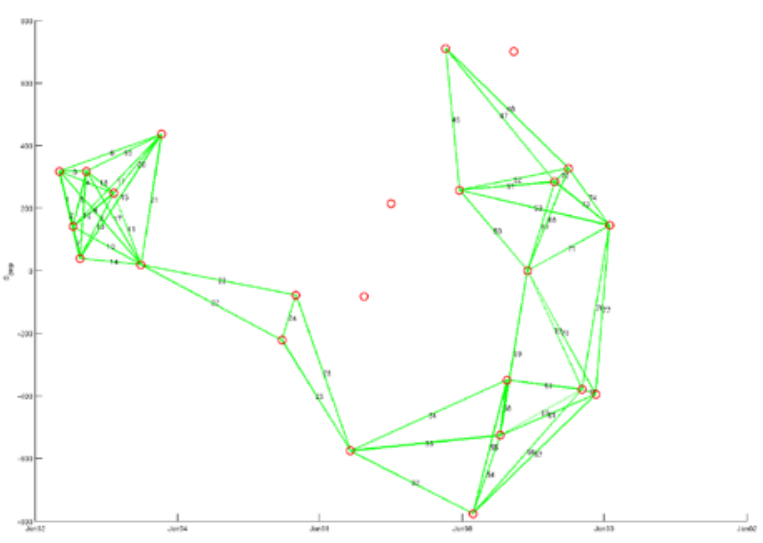

Figure 8. Temporal vs. spatial baseline distribution for the ERS-1/2 data in the SB processing.

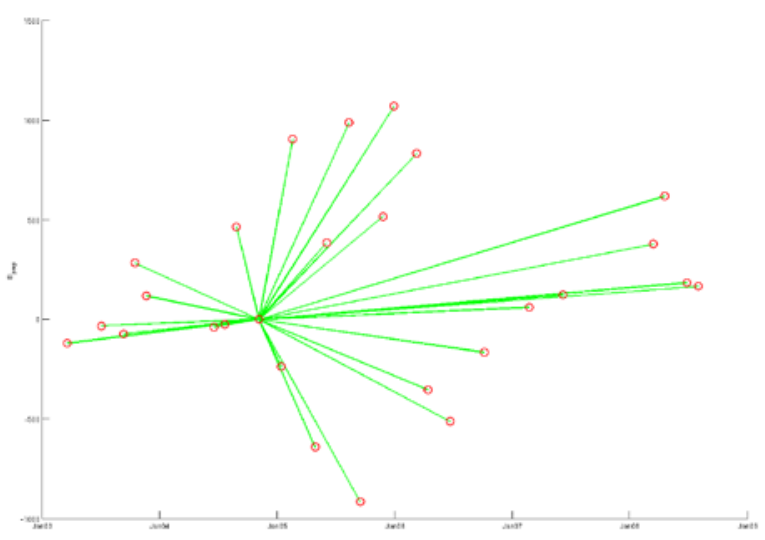

Figure 9. Temporal vs. spatial baseline distribution for the Envisat data in the PSI processing.

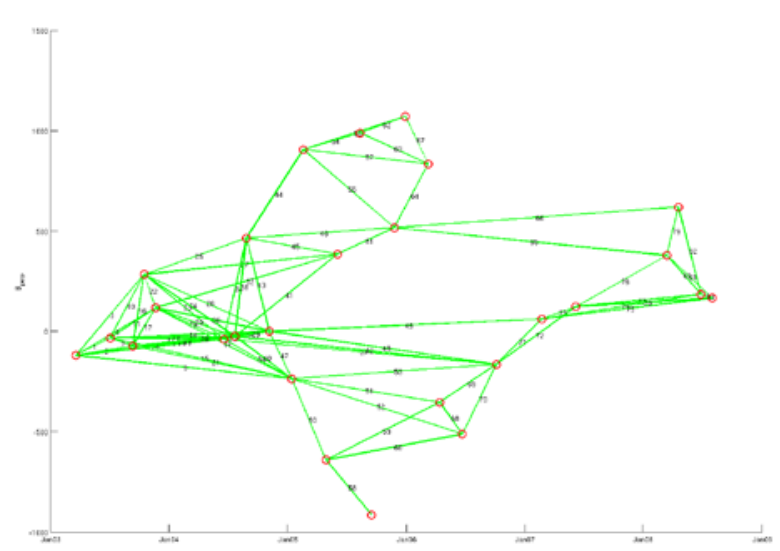

Figure 10. Temporal vs. spatial baseline distribution for the Envisat data in the SB processing.

After phase unwrapping step and filtering spatiallycorrelated noise, a mean velocity line-of-sight LOS rates for each persistent scatterer is calculated relative to a circular reference area (radius of $1 \mathrm{~km}$ ) located in a stable zone. This area corresponds to Sierra Gorda at the northwest part of the crops. In the SB and the combined processing, all the residuals between the unwrapped 
phase of the interferograms and the estimated ones when redundancy was removed by inverting to a single master network first were found to be in the $\pm \pi$ interval. This absence of spatially-correlated residuals clearly show the absence of unwrapping errors.

Figs. 11 and 13 show the combined processing (PSI+SB) time-series of the unwrapped phase in millimeters for each stack of interferograms referred to the first image for ERS-1/2 and Envisat respectively. The main faults as well as the Sierra Tejeda antiform are shown overlapped to the unwrapped phase for a better visualization of the results. In both cases, for ERS-1/2 and Envisat, the unwrapped phase is plotted in the range from $-40 \mathrm{~mm}$ to $+40 \mathrm{~mm}$. The temporal deformation pattern shows an homogeneous tendency in both timeseries indicating a subsidence of the Sierra Tejeda antiform, although this subsidence looks heterogeneous in time. In the same way, the Zafarraya Polje, located in the northwest part of the crop shows a subsidence in both periods.

The range of mean LOS velocities for the ERS-1/2 period (1992-2000) is between -4.2 and $+3.4 \mathrm{~mm} / \mathrm{yr}$ (Fig. 12). In the same way, for the Envisat period (20032008) it ranges from -5.0 to $+3.6 \mathrm{~mm} / \mathrm{yr}$ (Fig. 14).

\section{CONCLUSIONS}

Deformation in the southwestern Granada Depression and Sierra Tejeda areas provides homogeneous results in each geological region, with differences comparing the two analysed periods (1992-2000; 2003-2008). The most significant surprising result is that the main elevated areas (Sierra Gorda and Sierra Tejeda) undergone present-day subsidence for all the period in respect to the low relief areas (Granada basin and southwestern Sierra Tejeda).

In any case, the new data underline the fast subsidence of the Zafarraya Polje, probably as consequence of the activity of the Zafarraya normal fault located at its southern boundary. The data suggest a discontinuous behaviour, with practically no subsidence in the period 1999-2000 and a later fast subsidence during 20032008, supporting a probable heterogeneous displacement more typical of seismic faults.

Although this main insight needs further checks by other geodetical methods, it may be a consequence of the recent extensional regime that occurs at shallow crustal levels.

\section{ACKNOWLEDGEMENTS}

SAR data are provided by the European Space Agency (ESA) in the scope of 28654 G-POD CAT-1 project. This research was supported by ESP2006-28463-E, AYA2010-15501 projects from Ministerio de Ciencia e Innovación (Spain). In addition, it was supported by the
RNM-282 and RNM148 research groups and the P09RNM-5388 project from Junta de Andalucía (Spain). Interferometric data were processed using the public domain SAR processor DORIS and StaMPS/MTI. The DEM is freely provided by (C) Instituto Geográfico Nacional de España. The satellite orbits used are from Delft University of Technology and ESA.

\section{REFERENCES}

1. De Mets, C., Gordon, R.G., Argus, D.F. \& Stein, S. (1990). Current plate motions. Geophys. J. Int., 101, 425- 478 .

2. Grützner, C., Ruano, P., Jabaloy, A., GalindoZaldívar, J., Becker-Heidmann, P., Sanz de Galdeano, C., Rudersdorf, A., \& Reicherter, K. (2013). Late Holocene rupture history of the Ventas de Zafarraya Fault (Southern Spain). Cuaternario y Geomorfología, 27 (3-4), 5-32

3. Hanssen, R.F. (2001). Radar interferometry: data interpretation and error analysis. Vol. 2. Springer Science \& Business Media.

4. Hooper, A. (2008). A multi-temporal InSAR method incorporating both persistent scatterer and small baseline approaches, Geophys. Res. Lett. (35), L16, 302, doi:10.1029/2008GL03465.

5. Ferretti, A., Prati, C. \& Rocca, F. (2001). Permanent Scatters in SAR Interferometry. IEEE Transactions on Geoscience and Remote Sensing, 39(1), 8-20.

6. Kampes, B. M. (2005). Displacement Parameter Estimation using Permanent Scatterer Interferometry, PhD Thesis, Delft University of Technology.

7. Hooper, A., Segall, P. \& Zebker, H. (2007). Persistent scatterer InSAR for crustal deformation analysis with application to Volcán Alcedo, Galápagos, J. Geophys. Res. Lett., 112 (B07407), doi:10.1029/2006JB004763.

8. Berardino, P., Fornaro, G., Lanari, R. \& Sansosti, E. (2002). A new algorithm for surface deformation monitoring based on small baseline differ-ential SAR interferograms. IEEE Transactions on Geoscience and Remote Sensing. 40(11), $2375-83$.

9. Bekaert, D.P.S., Hooper, A. \& Wright, T.J. (2015). A spatially variable power law tropospheric correction technique for InSAR data, J. Geophys. Res. Solid Earth, 120, 
doi:10.1002/2014JB011558.

10. Scharroo, R. \& Visser, P. (1998). Precise orbit determination and gravity field improvement for
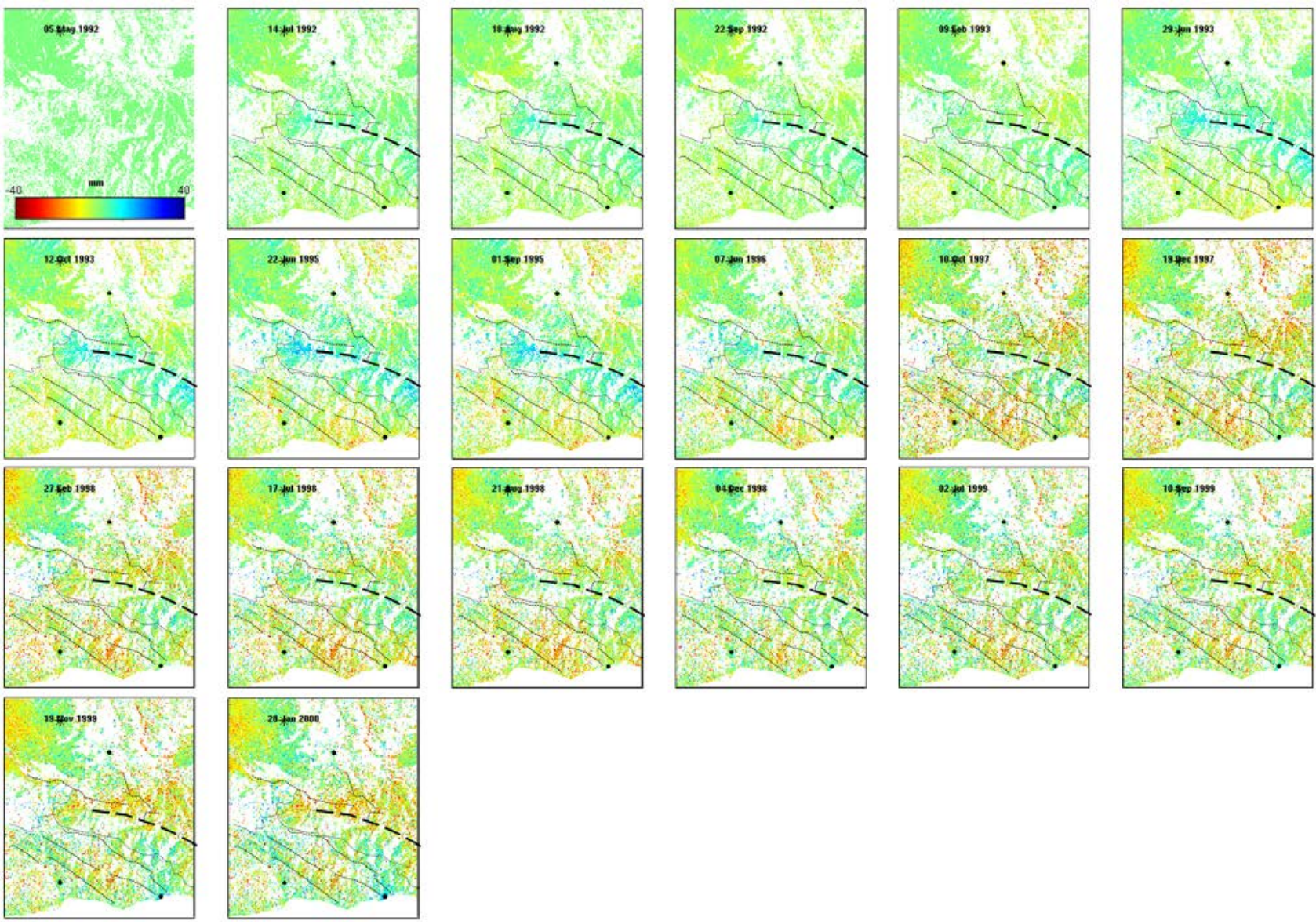

the ERS satellites, J. Geophys. Res.,

103 8113-8127, doi:10.1029/97JC03179.

Figure 11. Unwrapped phase for the combined $(P S I+S B)$ processing for the ERS-1/2 data referred to the fist data. All the single master interferograms are ordered by dates from left to right and top to bottom. The unwrapped phase is represented in millimetres.

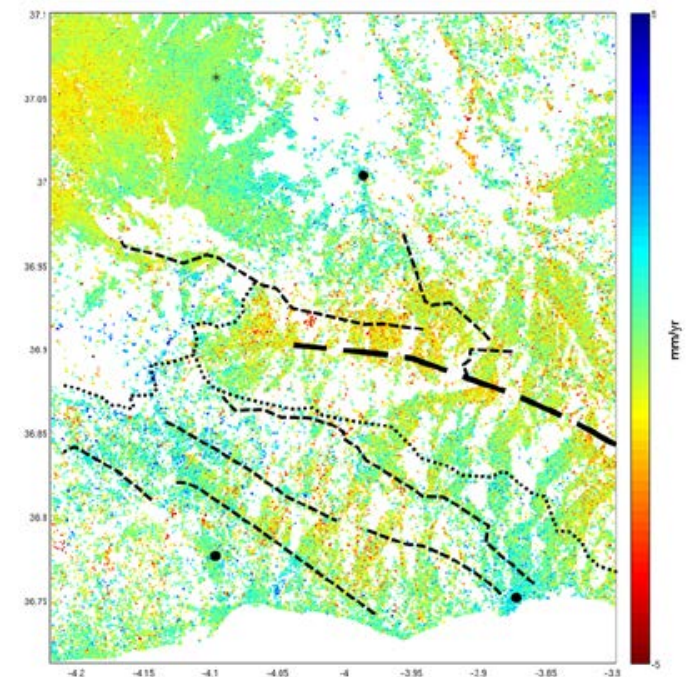

Figure 12. Mean LOS velocity for the combined (PSI+SB) processing for the ERS-1/2 data. 

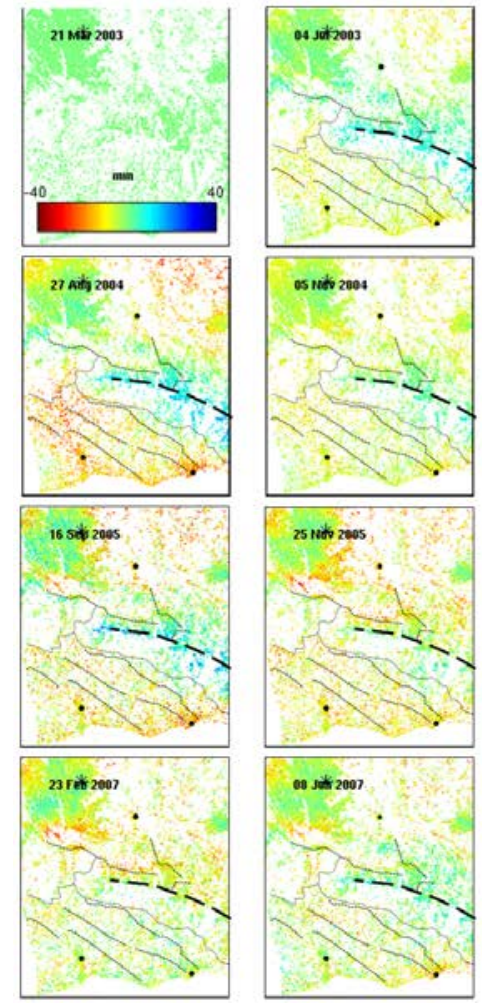
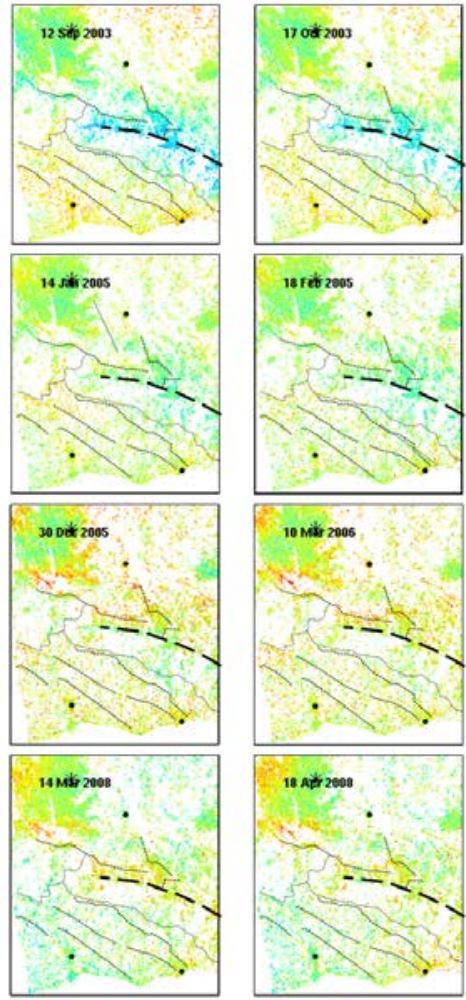
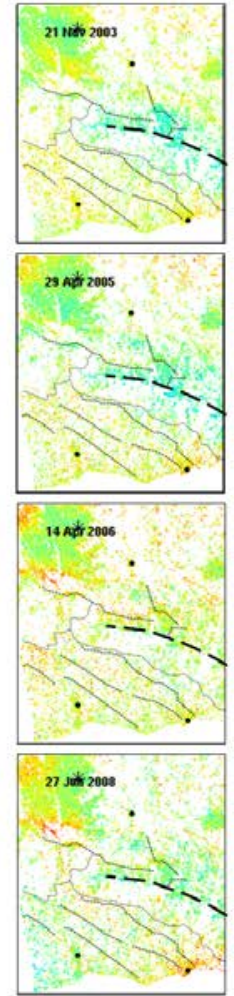
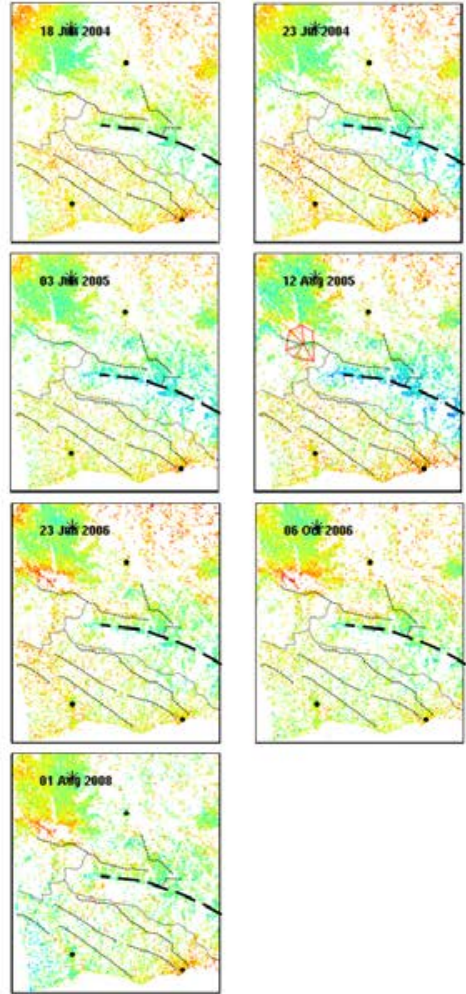

Figure 11. Unwrapped phase for the combined $(P S I+S B)$ processing for the Envisat data referred to the fist data. All the single master interferograms are ordered by dates from left to right and top to bottom. The unwrapped phase is represented in millimetres.

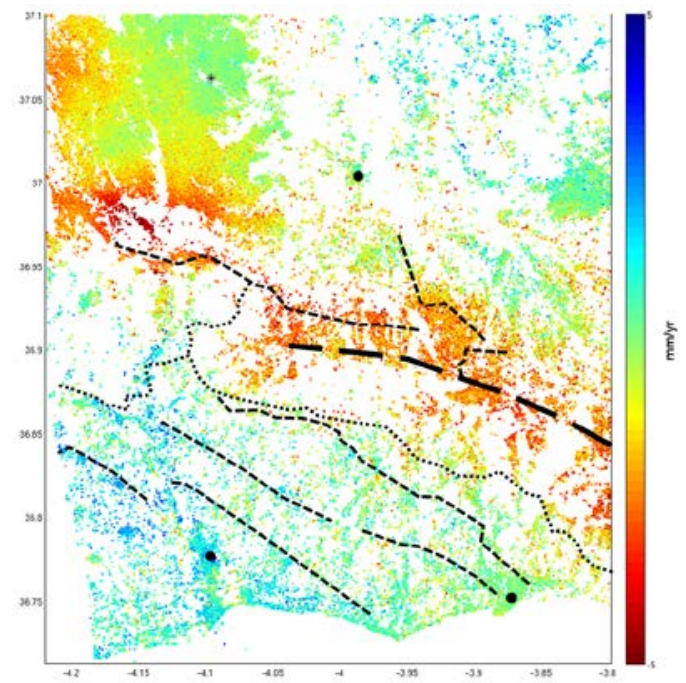

Figure 14. Mean LOS velocity for the combined (PSI+SB) processing for the Envisat data. 